\title{
Independent jejunal mechanisms for glycine and glycylglycine transfer in man in vivo
}

\author{
By G. C. COOK \\ Department of Medicine, The University of Zambia, PO Box 2379, Lusaka, Zambia
}

(Received I7 May 1972-Accepted I8 January 1973)

\begin{abstract}
I. Rates of absorption of glycine and glycylglycine from a $300 \mathrm{~mm}$ jejunal segment were compared in vivo when those compounds were given alone or together to six Zambian African subjects who had no clinical evidence of malnutrition or of gastro-intestinal disease. Solutions containing (A) glycine (100 mmol/1), (B) glycine ( $100 \mathrm{mmol} / \mathrm{l})+\mathrm{glycylglycine}(50 \mathrm{mmol} / \mathrm{l})$, and (C) glycylglycine $(50 \mathrm{mmol} / \mathrm{l})$ were infused into the upper jejunum by means of a doublelumen tube perfusion system.

2. Rate of absorption of glycine was significantly higher from the glycylglycine solution (C) than from the glycine solution (A). Glycine absorption rate from solution $\mathbf{B}$ (glycine + glycylglycine) was very similar to the sum of absorption rates of glycine from solutions $A$ and $C$ in each subject. Luminal disappearance rate of glycylglycine from solutions $C$ and $B$ were very similar; however, the rate was significantly greater than the total glycine absorption rate from solution $\mathbf{C}$ and indicates back-diffusion of glycine into the lumen after glycylglycine hydrolysis.

3. The results ate interpreted as indicating that the transport mechanisms for glycine and glycylglycine in man are partly, and possibly wholly, separate.
\end{abstract}

During the last 5 years evidence has accumulated suggesting that in both man and the rat glycine peptides are absorbed at a greater rate than glycine (Craft, Geddes, Hyde, Wise \& Matthews, I968; Matthews, Craft, Geddes, Wise \& Hyde, 1968). The practical importance of that observation is not yet clear; it is possible, however, that peptide absorption is quantitatively more important than amino acid absorption. It seems likely that glycylglycine dipeptidase activity is located mainly in the cell cytosol of the jejunal epithelium (Peters, 1970). In the present investigation, using a doublelumen tube jejunal perfusion system, the rates of absorption of glycine and glycylglycine have been compared in vivo in six Zambian African subjects, when those compounds were given alone and together.

\section{EXPERIMENTAL}

\section{Subjects studied}

Table I gives clinical details of the six Zambian African subjects. They were all in-patients at The University Teaching Hospital, Lusaka, and they agreed to undergo investigation after the procedure had been explained to them. None of the subjects showed clinical evidence of malnutrition or of gastro-intestinal disease. Table I also gives values for haemoglobin, serum albumin and globulin concentrations, and the results of an examination of the stool for parasites. A biopsy sample was taken from the jejunum of subject 4; it appeared normal under the dissecting microscope. Results of histological examinations were also normal for an African subject (Cook, Kajubi \& Lee, 1969). 


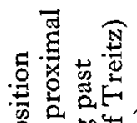

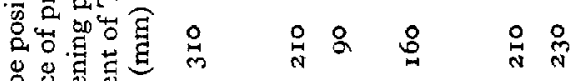

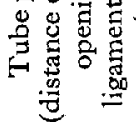

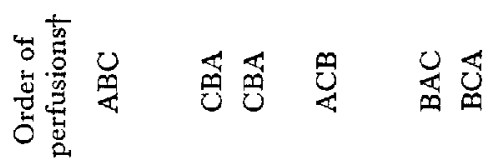

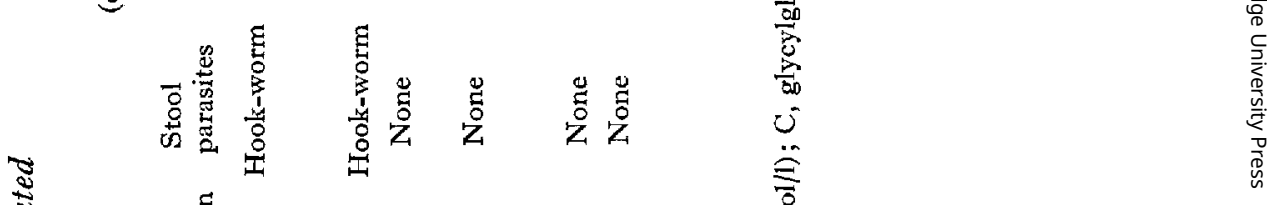

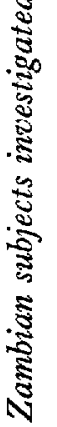

(2)

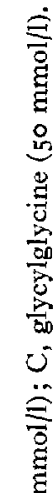

递票

表

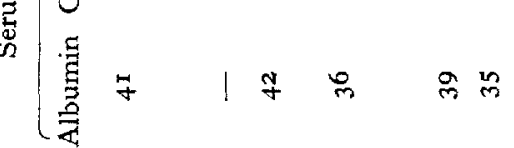

营

웅

- 를

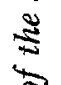

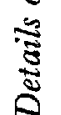

है

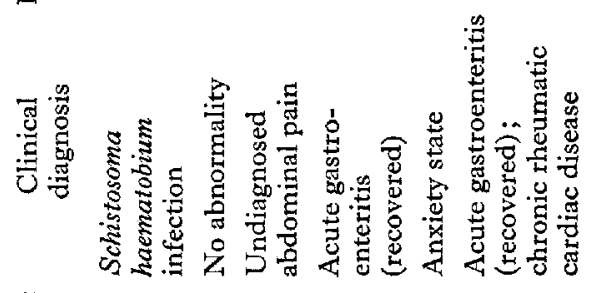

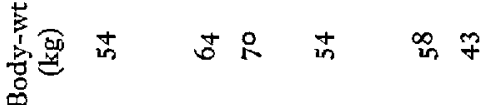

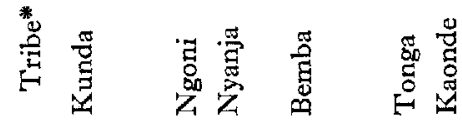

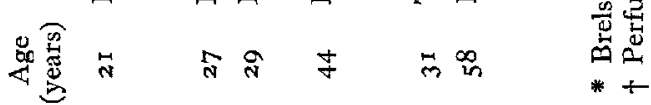

总蓠 


\section{Perfusion technique}

The perfusion method used has been described previously (Cook, 1971, 1973). A double-lumen tube with a mercury weight attached at the distal end was swallowed on the evening before the test. The tube contained a proximal opening into one lumen, positioned $300 \mathrm{~mm}$ from the end, through which the perfusing fluid was pumped at $12.0 \mathrm{ml} / \mathrm{min}$ by a constant-infusion pump, and three openings into the other lumen at the distal end. The tests were performed after a $14^{-1} 8 \mathrm{~h}$ overnight fast during which sips of water were permitted. The tube was examined radiographically and the position of the proximal opening in relation to the ligament of Treitz is shown in Table $\mathrm{I}$. A further radiograph was taken after completion of the study, and the distal movement of the proximal opening was found to be less than $50 \mathrm{~mm}$. Each subject was perfused with (A) glycine (100 mmol/l), (B) glycine (100 $\mathrm{mmol} / \mathrm{l})$ and glycylglycine $(5 \circ \mathrm{mmol} / \mathrm{l})$, and $(\mathrm{C})$ glycylglycine $(50 \mathrm{mmol} / \mathrm{l})$. All solutions were made isotonic with sodium chloride, and they also contained polyethylene glycol (PEG) (mol. wt 4000, 5.00 g/l) as a non-absorbable marker. The sequence of the perfusions was varied in the different subjects (Table $\mathrm{r}$ ). After an equilibration period of $35 \mathrm{~min}$, three successive ro $\mathrm{min}$ collections of intestinal contents were made by siphoning through the distal end. Perfusion with the three solutions followed directly after each other. All samples of intestinal fluid were immediately frozen and stored for assay.

\section{Analytical methods and calculation of results}

Glycine was estimated by the method of Giroux \& Puech (1963) and glycylglycine was estimated as glycine by the same method after hydrolysis (Matthews et al. 1968). For solution B and the intestinal samples obtained during its infusion, the concentration of free glycine was determined before hydrolysis, and that of glycine present as glycylglycine was taken to be the difference between the values obtained for glycine before and after hydrolysis. PEG was estimated by a turbidimetric method (Hydén, 1955). The concentrations of glycine (before and after hydrolysis) and PEG were estimated for all perfusion fluids and for all samples of intestinal contents; triplicate determinations were made for glycine, and duplicate determinations for PEG.

The rates of absorption of glycine from solutions of glycine and glycylglycine, or both, were calculated from a standard formula (Cook, 1972a). The rate of net water absorption was calculated from values obtained for concentrations of PEG in the siphoned intestinal samples (Cook, 1971).

The levels of reproducibility for the rates of total glycine absorption for the three Io min collections of intestinal contents were as follows: for solution A, the SD was $9.7 \mathrm{mg} / \mathrm{min}$ per $300 \mathrm{~mm}$ jejunum and the coefficient of variation was $20 \%(n=6)$; for solution $B$, the SD was $6.2 \mathrm{mg} / \mathrm{min}$ per $300 \mathrm{~mm}$ jejunum and the coefficient of variation was $5 \%(n=6)$; for solution $\mathrm{C}$, the $\mathrm{SD}$ was $6.9 \mathrm{mg} / \mathrm{min}$ per $300 \mathrm{~mm}$ jejunum and the coefficient of variation was $10 \%(n=6)($ Cook, $1972 a)$. For net water absorption, the SD was $\mathrm{I} \cdot 3 \mathrm{I} \mathrm{ml} / \mathrm{min}$ per $300 \mathrm{~mm}$ jejunum $(n=\mathrm{I} 8)$. 


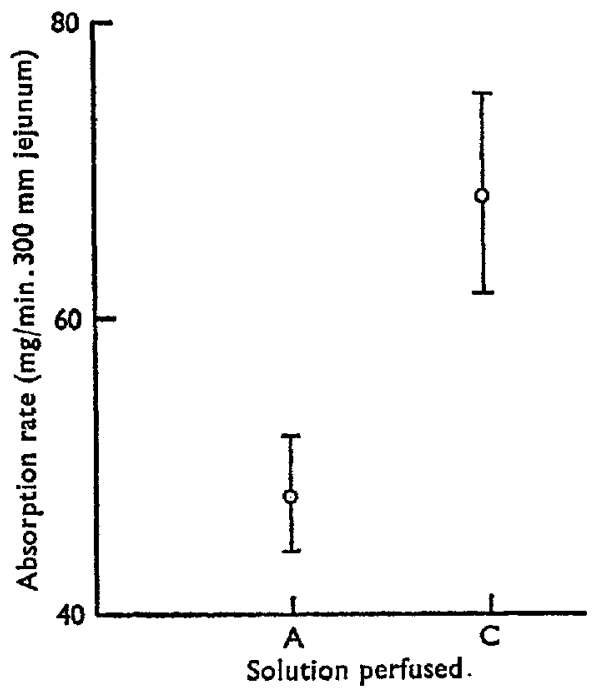

Fig. I. Glycine absorption rates from the glycine (A) and glycylglycine (C) solutions in the six Zambian subjects. The vertical bars represent the standard errors of the means. These results have previously been reported in detail (Cook, $1972 b$ ).

Table 2. Comparison of total glycine absorption rate from the glycine $(A)+$ glycylglycine $(C)$ solutions, with that from the glycine and glycylglycine solution $(B)$ in the six Zambian subjects

From solution $\mathrm{A}+$ solution $\mathrm{C}$

Subject no.

I
2
3
4
5
6
Mean

(mg/min per $300 \mathrm{~mm}$ jejunum)

I 17
I 40
I 38
72
97
I33
I 6.2

From solution B (mg/min per $300 \mathrm{~mm}$ jejunum)

RESULTS

Table 2 summarizes the comparative rates of absorption of glycine from solutions $A+C$, and from solution B, in the six subjects. Total glycine absorption rates were very similar when glycine and glycylglycine were given alone or together. Fig. I shows that there was a significantly greater absorption rate of glycine from the glycylglycine solution (C) than from the glycine solution (A) in the six subjects $(t=7$. I I $P<0.001$; $\mathrm{df}=5$ ) (paired $t$ test) (Cook, 1972b). All subjects were found to have a higher rate of glycine absorption from glycylglycine than from glycine. The lowest rates of absorption for both glycine and glycylglycine were in subjects 4 and 5. Incubation of intestinal contents containing glycylglycine at $37^{\circ}$ for $\mathrm{i} 2 \mathrm{~h}$ failed to demonstrate glycylglycine dipeptidase activity; Table 3 shows that the rate of luminal disappearance of glycine from glycylglycine in solution $\mathrm{B}$ and in solution $\mathrm{C}$ was very similar in the six subjects and it was significantly higher than the rate of total glycine absorption from solution 
Table 3. Glycine absorption rate from the glycylglycine solution $(C)$, and comparison of the luminal disappearance rates of glycylglycine from solution $C$ with that from solution $B$ (glycylglycine + glycine) in the six Zambian subjects

$\begin{array}{cccc}\text { Subject no. } & \begin{array}{c}\text { Absorption rate from solution C } \\ \text { (mg/min per 300 mm jejunum) }\end{array} & \text { Sisappearance rate } \\ \text { I } & 67 & 85 & 82 \\ 2 & 83 & 85 & 90 \\ 3 & 80 & 86 & 89 \\ 4 & 40 & 63 & 68 \\ 5 & 6 \circ & 87 & 9 \circ \\ 6 & 80 & 89 & 85 \\ \text { Mean } & 68 \cdot 3 & 82 \cdot 5 & 84.0\end{array}$

C (for solution C, $t=3.47 ; P<0.02$; $\mathrm{df}=5$, and for solution $\mathrm{B}, t=3.53$; $P<0.02 ; \mathrm{df}=5$ ) (paired $t$ tests).

The mean net rates of absorption of water from the three solutions were $(\mathrm{ml} / \mathrm{min}$ per $300 \mathrm{~mm}$ jejunum) $: 0.45(\mathrm{SEM}=0.87$ ) for solution $\mathrm{A} ; \mathrm{I} .83(\mathrm{SEM}=0.49)$ for solution $\mathrm{B}$; and $\mathrm{r} \cdot 74$ (SEM $=0.77$ ) for solution $\mathrm{C}$. These values show that the mean rate of absorption of water from solution $A$ was lower than that from solutions $B$ and $C$; none of the differences between the rates was significant by Student's $t$ test.

\section{DISCUSSION}

This study shows that in man the transport mechanisms for glycine and glycylglycine, in vivo, are partly, and possibly wholly, independent. The sum of the rates of absorption for glycine and glycylglycine, when each compound was given alonc, was very similar to the rate of absorption of glycine from the solution containing both glycine and glycylglycine (B) (Table 2). Glycine absorption in man has been shown to conform to saturation kinetics (Cook, $1972 b$, I973). In both studies, Lineweaver \& Burk (1934) plots of the rates of absorption of glycine from glycine solutions ranging in concentration from 50 to $250 \mathrm{mmol} / 1$ gave straight lines. In the present study, the mean rate of absorption of glycine from the solution containing $100 \mathrm{mmol}$ glycine/ 1

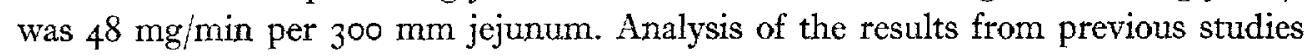
(Cook, $1972 b$, 1973) shows that at a glycine concentration of $200 \mathrm{mmol} / 1$ in the perfusion fluid (equivalent to all the glycine present in solution B) the mean rate of absorption for glycine would be approximately $70 \mathrm{mg} / \mathrm{min}$ per $300 \mathrm{~mm}$ jejunum. In fact the mean rate of absorption of glycine from solution $B$ in the present study was approximately $120 \mathrm{mg} / \mathrm{min}$ per $300 \mathrm{~mm}$ jejunum. The rate of absorption of glycylglycine has been shown in the present study, and also by Cook (1972b), to be significantly greater than that of glycine, but a kinetic curve has not been constructed.

It is not certain whether there are separate transfer mechanisms for amino acids and peptides, or whether they share the same mechanism (Matthews, 1971). Some previous studies in the rat have suggested that amino acids and peptides share the same mechanism (Newey \& Smyth 1962; Matthews et al. 1968; Matthews, Lis, Cheng \& 
Crampton, 1969). Lis, Crampton \& Matthews (1972) have shown, also in the rat, that methionine and its dipeptide use separate mucosal uptake mechanisms. Rubino, Field \& Shwachman (1970) have presented evidence that in the rabbit ileum, in vitro, amino acids have a low affinity for the peptide transfer system. In Hartnup disease there is good evidence that amino acids and peptides use separate mechanisms, at least in part (Asatoor, Cheng, Edwards, Lant, Matthews, Milne, Navab \& Richards, 1970). In the latter investigation, using oral tolerance tests, higher blood concentrations of tryptophan and phenylalanine were obtained in a patient with Hartnup disease when those amino acids were given in the form of the dipeptides glycyltryptophan and phenylalanylphenylalanine. In the present study, in six men who had no evidence of malnutrition or of gastro-intestinal disease, uptake mechanisms which must have been largely, if not wholly, separate for glycine and glycylglycine have been demonstrated.

The rate of disappearance of glycylglycine from the jejunal lumen during the perfusion of solution $\mathrm{C}$ exceeded the total glycine absorption rate from that solution, and the difference between the means was significant (Table 3). The rate of disappearance from solutions $\mathrm{C}$ and $\mathrm{B}$ was very similar, and in both solutions approached the maximum rate for the investigation $(90 \mathrm{mg} / \mathrm{min}$ per $300 \mathrm{~mm}$ jejunum). This must indicate that the rate of hydrolysis of glycylglycine significantly exceeded the maximum rate of glycine absorption and that back-diffusion of glycine to the lumen had occurred. This observation suggests that glycylglycine hydrolysis occurs, partly at least, near the luminal part of the enterocyte, and possibly in the brush-border region. Whether that observation applies to other dipeptides is not known.

Absorption of protein as peptide rather than amino acid may be of practical importance in the rat (Crampton, Gangolli, Simson \& Matthews, 1971) and man (Nixon \& Mawer, $197^{\circ}$ ). In the former study, absorption of pancreatic hydrolysates, consisting of small peptides and amino acids, was shown to be more rapid than the absorption from corresponding mixtures of free amino acids. Nixon \& Mawer (1970) have shown that in man some dietary protein is absorbed in vivo in a form other than free amino acids. The present study suggests that there are independent transfer mechanisms for amino acids and dipeptides. The fact that peptide absorption rates are only slightly higher than those of amino acids suggests that both mechanisms are important in man, and it seems likely that both transfer mechanisms function simultaneously. It seems likely that a mixture of amino acids and peptides leads to the highest rate of absorption of amino acids. In subjects with severe malnutrition and malabsorption, it would presumably be preferable to give protein as peptides rather than as amino acids if a rapid rate of absorption is required, although the most efficient way of giving protein supplements would be to give mixtures of amino acids and peptides. Unless the jejunal mucosa is very severely damaged, however, that is unlikely to assume practical importance.

I thank Mr James Tembo for help with the patients. Financial support from the Reverend W. H. Woodhouse and The University of Zambia Research Fund is gratefully acknowledged. 


\section{REFERENCES}

Asatoor, A. M., Cheng, B., Edwards, K. D. G., Lant, A. F., Matthews, D. M., Milne, M. D., Navab, F. \& Richards, A. J. (1970). Gut II, 380.

Brelsford, W, V. (1965). The Tribes of Zambia. Lusaka, Zambia: Government Printer.

Cook, G. C. (1971). F. Physiol, Lond. $217,6 \mathrm{r}$.

Cook, G. C. (1972 a). Clin. Sci. 42, 525.

Cook, G. C. $(1972$ b). Clin. Sci. 43, 443.

Cook, G. C. (1973). Br. F. Nutr, 29, 377.

Cook, G. C., Kajubi, S. K. \& Lee, F. D. (I969). F. Path. 98, 157.

Craft, I. L., Geddes, D., Hyde, C. W., Wise, I. J. \& Matthews, D. M. (I 968). Gut 9, 425.

Crampton, R. F., Gangolli, S. D., Simson, P. \& Matthews, D. M. (I97I). Clin. Sci. 41, 409.

Giroux, J. \& Puech, A. (1963). Annls pharm. fr. 21, 469.

Hydén, S. (1955). K. LantbrHögsk. Annlr. 22, 139.

Lineweaver, H. \& Burk, D. (1934). F. Am. Chem. Soc. 56,658.

Lis, M. T., Crampton, R. F. \& Matthews, D. M. (1972). Br. F. Nutr. 27, I 59.

Matthews, D. M. ( 97 I). F. clin. Path. 24, Suppl. no. 5, p. 29.

Matthews, D. M., Craft, I. L., Geddes, D. M., Wise, I. J. \& Hyde, C. W. (1968). Clin. Sci. 35, 4r 5.

Matthews, D. M., Lis, M. T., Cheng, B. \& Crampton, R. F. (I969). Clin. Sci. 37, 75 r.

Newey, H. \& Smyth, D. H. (1962). $\mathscr{F}$. Physiol., Lond. 164, 527.

Nixon, S. E. \& Mawer, G. E. (1970). Br. F. Nutr. 24, 24I.

Peters, T. J. (1970). Gut 11, 720.

Rubino, A., Field, M, \& Shwachman, H. (1970). Pediat. Res. 4, 477. 